“C 2019 IEEE. Personal use of this material is permitted. Permission from IEEE must be obtained for all other uses, in any current or future media, including reprinting/republishing this material for advertising or promotional purposes, creating new collective works, for resale or redistribution to servers or lists, or reuse of any copyrighted component of this work in other works." 


\section{Active Utilization of a Full DC-Link Voltage in Multilevel Converter}

\author{
Yam P. Siwakoti \\ Faculty of Engineering and Information \\ Technology \\ University of Technology Sydney \\ Sydney, Australia \\ email:yam.siwakoti@uts.edu.au
}

\author{
Akshay Mahajan \\ Department of Power Electronics \\ Fraunhofer Institute for Solar Energy \\ Systems (ISE) \\ Freiburg, Germany \\ email: akshay.mahajan@ise.fraunhofer.de
}

\author{
Stephan Liese \\ Department of Power Electronics \\ Fraunhofer Institute for Solar Energy \\ Systems (ISE) \\ Freiburg, Germany \\ email: stephan.liese@ise.fraunhofer.de
}

\begin{abstract}
Multilevel inverter technology has emerged recently as a very important alternative in the area of high-power medium-voltage energy conversion. Multilevel inverter reduces the inductors and filters size, whilst improving the output power quality. However, the main drawback of the multi-level inverter topologies is that they utilizes only $\leq 50 \%$ of the input dc-bus voltage, i.e. they require two times the peak of ac output voltage. For example, the nominal input voltage of the NPC, ANPC and Flying Capacitor is $800 V_{d c}$. This high dc-link voltage not only requires higher voltage components (both active and passive) but also prompts to use an additional front-end boost dc-de converter. Considering these aspects, this paper presents a novel technique to extend the input dc-bus voltage utilization in any conventional multilevel inverter from $\leq 50 \%$ to $\leq 100 \%$. The novel technique utilizes an additional T-type module (consist of four active switches), which is inserted just before the two dc-link capacitor forming a new grounding point. The novel method not only reduces the input voltage requirement and voltage stress, but also increases the output voltage levels of the inverter. In general, this technique can be implemented to any multilevel inverter. An example of implementation of $5 \mathrm{~L}$ inverter from the conventional 3-Level T-type inverter is discussed and validated. Measurement results shows that the new Dual T-type inverter has a flat efficiency $\approx 99 \%$ over a wide range of load.
\end{abstract}

Keywords-Multilevel Converter, T-type inverter, ActiveNeutral-Point Clamped (ANPC) Inverter, Flying Capacitor, Pulse-Width-Modulation (PWM).

\section{INTRODUCTION}

Many multilevel converter topologies have been reported in the literature since 1970s, yet there are still new topologies coming out, finding applications in emerging areas [1]. There are mainly three types of classic multilevel inverter topologies: Neutral Point Clamped (NPC) type, Flying-Capacitor (FC) type, and hybrid structure consisting of H-bridge and NPC and/or FC [1]-[6]. Besides various advantages of multilevel inverter such as reduced output harmonics, lower $d v / d t$, and switching loss; the main drawback of the multilevel inverter is the poor utilization factor of the input dc-link voltage. In any conventional multilevel inverter, the input voltage requirement is at least two times the peak of the ac output voltage as shown in Fig. 1. This means the input dc voltage utilization factor is $\leq$ $50 \%$, compared to two level H-bridge type inverter with dc- link voltage utilization up to $100 \%$. This higher input voltage requirement in multilevel inverter not only demands additional front-end boost dc-dc converter, but also increase the cost and size of the of the overall system design.

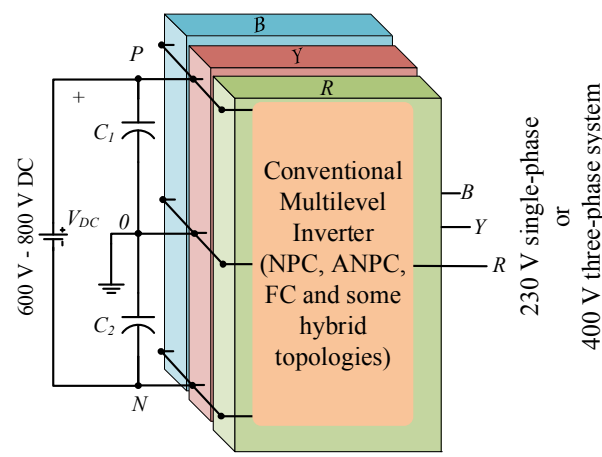

(a)

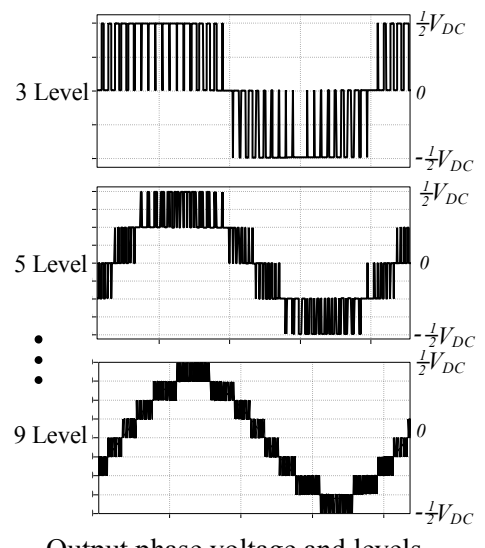

Output phase voltage and levels

(b)

Fig. 1. Illustration of dc-link voltage utilisation of conventional multilevel converters.

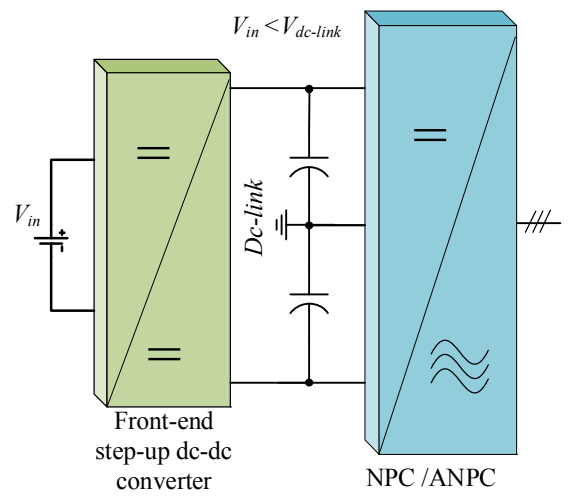

(a) 


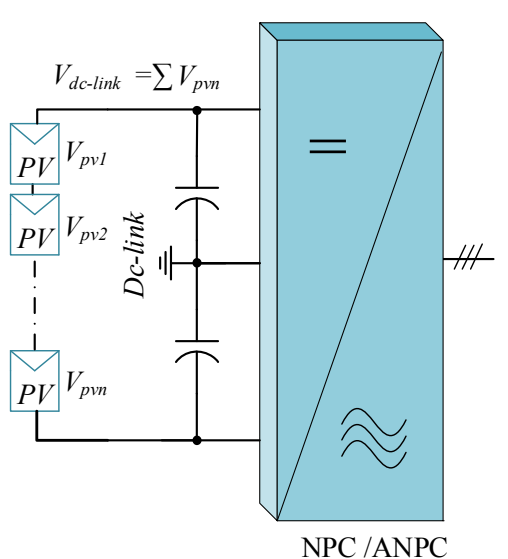

(b)

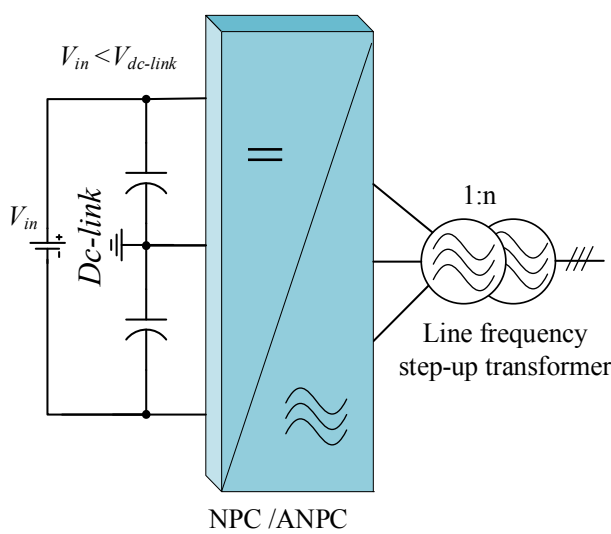

(c)

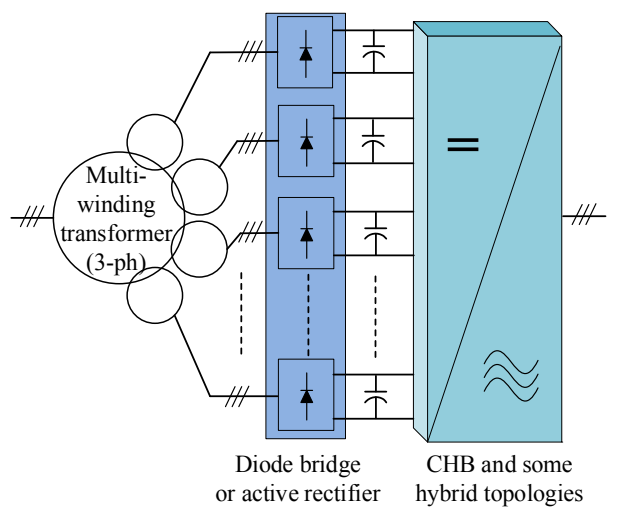

(d)

Fig. 2. Examples of front end dc-link supply for some of the common multilevel converters: (a) using a front-end step-up dc-dc converter, when $V_{\text {in }}<V_{\text {dc-link }}$, (b) connecting PV modules in series (string), where, $V_{d c-l i n k}=\sum V_{P V n}$, (c) using a line frequency step-up transformer at the output, when $V_{i n}<V_{d c-l i n k}$, (d) using a multi-winding transformer and diode-bridge (multi-pulse) or active-rectifier for CHB (isolated) and some hybrid topologies (isolated or non-isolated).

For many applications (e.g. a grid-connected PV system), the conventional multilevel converters may require an additional front-end boost dc-dc converter, or string of series-connected PV modules to raise the dc-link voltage (e.g. up to $800 \mathrm{~V}$ for connection to a $400 \mathrm{~V}$ grid). Examples of the front-end dc-link supply for some of the common multilevel converters are shown in Fig. 2. In general, these multi-stage power conversion approaches reduce system efficiency and reliability as shown in Fig. 3, whilst increasing the size and cost of the system. In the case of a PV system, the additional boost stage can be eliminated by connecting PV modules in series strings to produce a higher dc-link voltage, however this potentially reduces energy yield due to mismatch between the modules (e.g. as a result of shading) which will tend to offset the improved converter efficiency. Therefore, a single-stage dc-ac power converter with boost capabilities offers an interesting alternative compared to two-stage approach [1].

Considering this aspect, a novel technique is being developed in this paper for any multilevel converter to improve the input de voltage utilization from $50 \%$ to $100 \%$. The full input dc-bus voltage utilization reduces the dc-link voltage and hence the stress and cost on components by factor of two. Following sections describe the new technique in general with an application example of a conventional 3-level T-type inverter and 5L ANPC. The resulting 5-level Dual Ttype from $3 \mathrm{~L}$ inverter and $7 \mathrm{~L}$ from conventional $5 \mathrm{~L}$ is discussed in brief with supporting analysis and results.

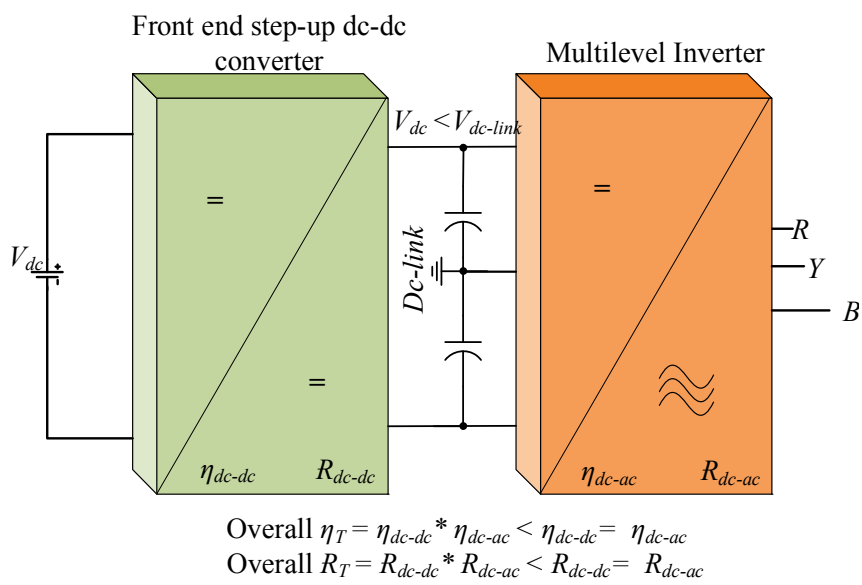

Fig. 3. Illustration of two-stage power conversion and its effect on the efficiency and reliability of the system.

\section{GENERAL IMPLEMENTATION}

Fig. 4 (a) shows the general implementation of the proposed method, where an additional T-section/module similar to the 3-level T-type inverter is inserted at the front side of the conventional inverter forming flipped T-type structure. The additional T-section consists of four switches $S_{1 T}, S_{2 T}, S_{3 T}$, and $S_{4 T}$. The common grounding is shifted from 0 to 0 ' by a bidirectional switch $S_{3} T$, and $S_{4 T}$, which helps to add common ground to the input dc supply voltage as and when required. This possibility of inclusion of input dc voltage level in the converter operation opens a new horizon in the development of higher-level multilevel inverter with $100 \%$ input dc-bus voltage utilization. Unlike conventional topologies where the output voltage level is a combination of dc-link capacitor voltage and the voltages in the consecutive capacitors (in case of multilevel inverter with $>3$-levels), the voltage level in the new inverter is the combination of capacitor voltages and the input voltage. For example, a new 5-L Dual T-type inverter as shown in Fig. 4(b) is being developed by adding a T-section/module on a conventional 3-L T-type inverter. The output voltage levels in the resultant inverter are combination of voltage across $V_{C 1}, V_{C 2}$ and the input dc voltage forming a 5-level output voltage $\left(0,+V_{d c} / 2,-V_{d c} / 2,+V_{d c}\right.$, and $\left.-V_{d c}\right)$, unlike only three levels in conventional 3-level T-type inverter $(0$, 


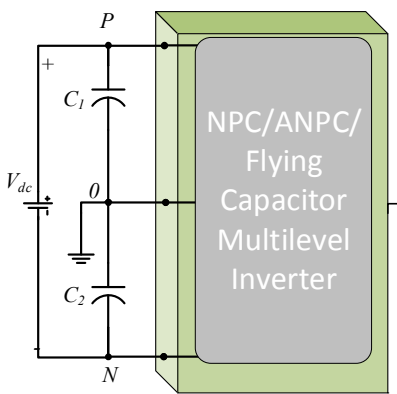

Conventional Multilevel Converter with dc-link voltage utilization $\leq 50 \%$

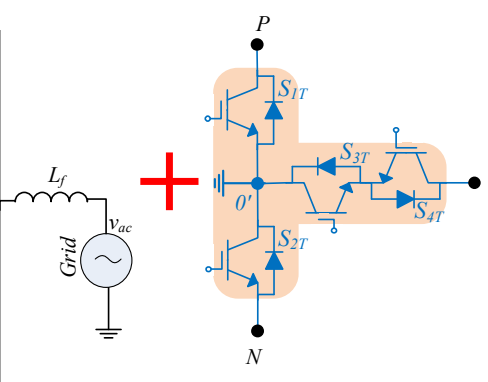

Additional T-Section/module

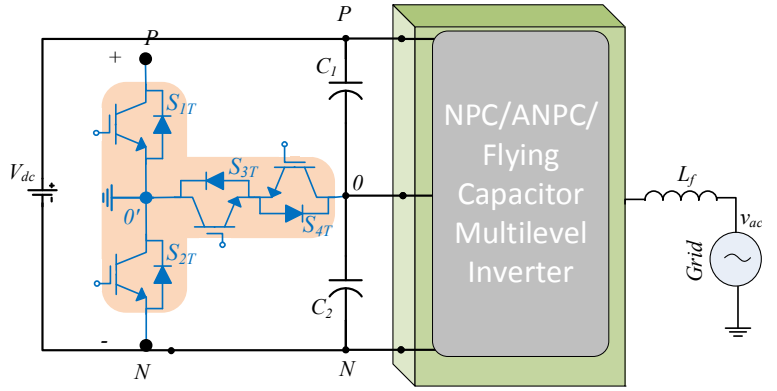

New Multilevel Converter with dc-link voltage utilization $\leq 100 \%$

(a)

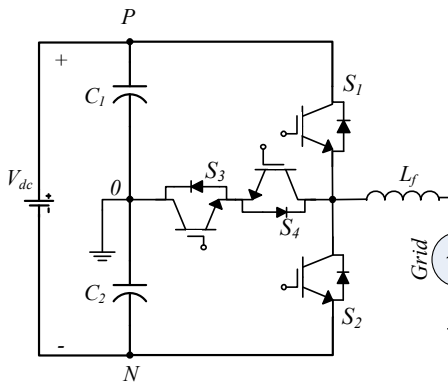

Conventional 3L T-Type inverter with dc-link voltage utilization $\leq 50 \%$

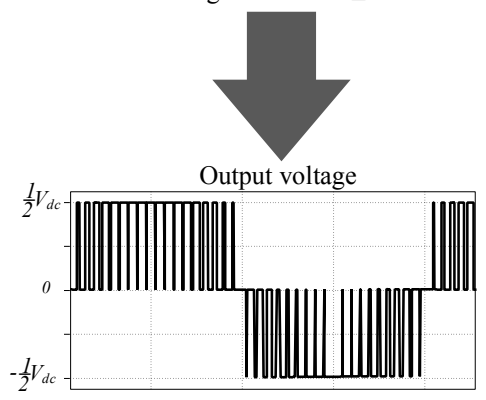

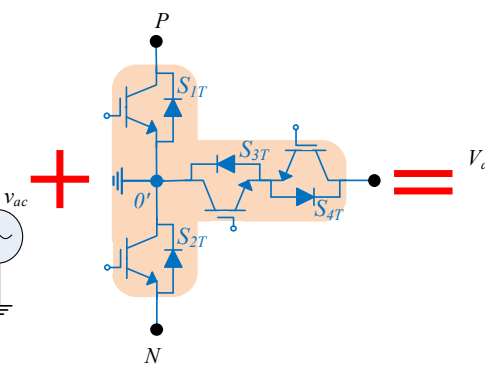

Additional T-Section/module

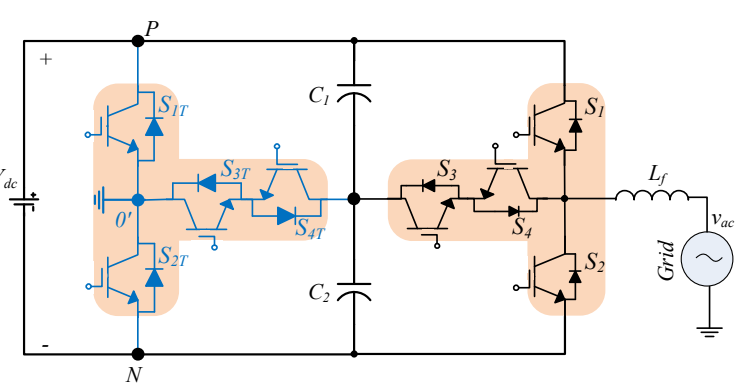

New 5L Dual T-Type inverter with dc-link voltage utilization $\leq 100 \%$

(b)

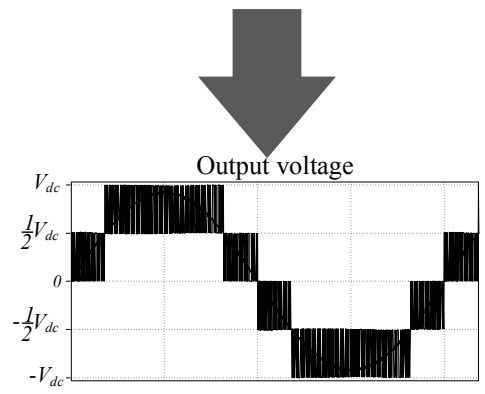

conventional NPC, ANPC, Flying Capacitor type multilevel inverter to improve the input voltage utilization to $100 \%$, (b) Illustration and implementation of proposed method for $3 \mathrm{~L}-\mathrm{T}$-type NPC inverter showing improvement in dc-link voltage utilization to $100 \%$.

$+V_{d c} / 2$, and $\left.-V_{d c} / 2\right)$ as shown in Fig. 4(b). This means that the peak of the ac output voltage in the resulting topology is same as of the magnitude of the input dc-bus voltage $\left(V_{\text {Peak-ac }}=V_{d c}\right)$; unlike conventional topology, where the peak of the ac output is half of the input dc-bus voltage $\left(V_{\text {Peak-ac }}=V_{d c} / 2\right)$.

An example of implementation of this technique to $5 \mathrm{~L}$ conventional inverter is also shown in Fig. 5. With this implementation a new $7 \mathrm{~L}$ inverter is generated with an improved dc-link voltage utilization.

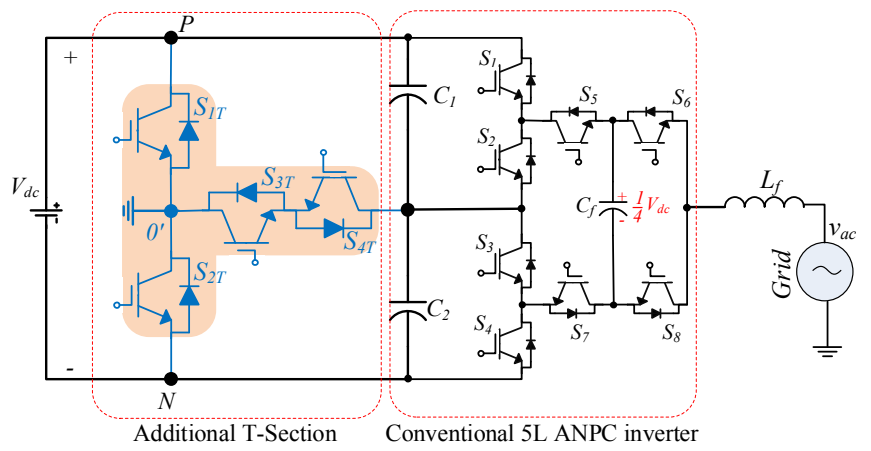

Fig. 5. New 7L inverter with in dc-link voltage utilization of $\leq 100 \%$.
In general, the improvement in the input dc-bus voltage utilization from $50 \%$ to $100 \%$ brings following advantages in the system design:

1) Reduces the input dc-link voltage $\left(V_{d c}\right)$ requirement by $50 \%$, i.e. it requires half of the input voltage compared to traditional NPC, ANPC and Flying Capacitor inverter family. This will have huge impacts on the system design, cost, efficiency, reliability and power density. This also helps to reduce the high voltage insulation and spacing requirements and offer better voltage waveforms at the output.

2) Reduction in input voltage means low voltage rated active and passive components (Max. $400 \mathrm{~V}$ on any component compared to $800 \mathrm{~V}$ in case of conventional topology), which not only reduce the cost of the components but also reduce volume.

3) In case of Dual 5L T-type inverter, two identical Ttype NPC modules can be used as the voltage stress/current stress is identical.

4) The resulting inverter increases the number of voltage levels, consequently reducing the size of the filter requirements.

5) The preliminary analysis shows a reduction of dc-link capacitance requirement by about $50 \%$. 


\section{COMPARISON AND DISCUSSIONS}

The above theoretical findings and analysis are finally validated in simulation and measurements. The respective nominal dc-bus voltage, i.e., $750 \mathrm{~V}-800 \mathrm{~V}$ for 3L T-type and $375 \mathrm{~V}-400 \mathrm{~V}$ for the new 5L Dual T-type is considered for simulation and measurement. Fig. 6 shows the comparative simulated results of both type of topologies as discussed above. Two single-phase prototypes of the conventional Ttype inverter and the Dual T-type inverter with power rating of $3.3 \mathrm{~kW}$ were also constructed and tested in the laboratory. Custom designed $\mathrm{SiC}$ Modules were implemented for the prototype design. It is evident that both inverter produce same output rms voltage and current for identical loads.

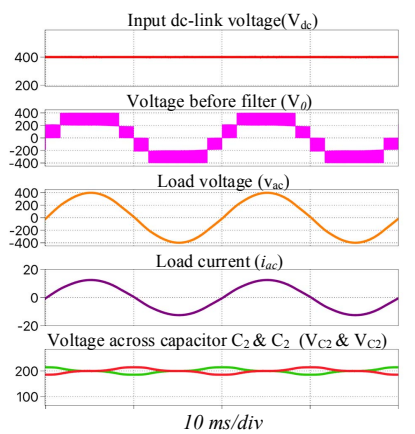

(a)

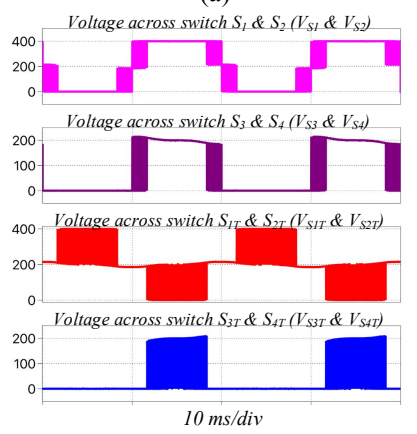

(c)

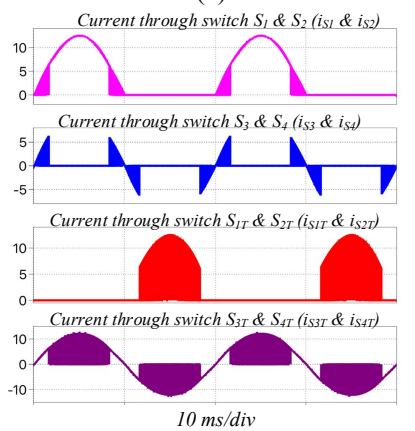

(e)

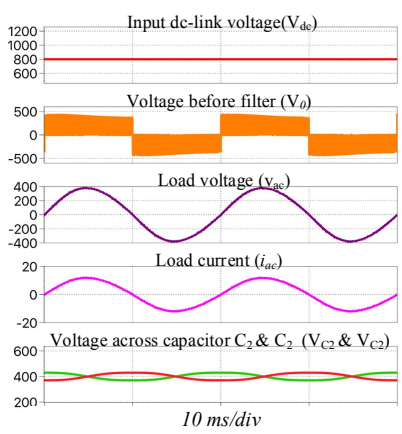

(b)

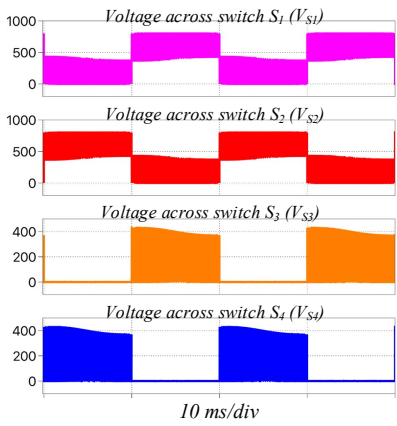

(d)

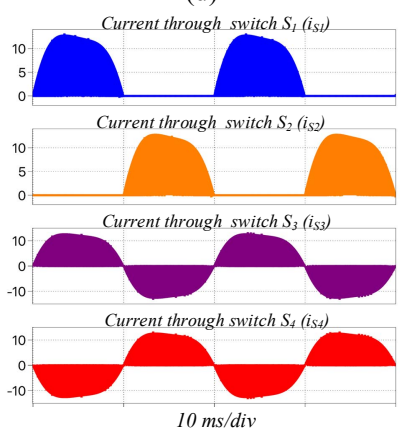

(f)
Fig. 6. Comparative simulated result of 5L Dual T-type inverter ((a), (c) \& (e)) and 3L T-Type inverter ((b), (d) \& (f)) showing: (a) \& (b) input voltage, output voltage levels and current and capacitor voltages, (c) \& (d) voltage stress on switches, and (e) \& (f) current stress on switches.

Fig. 7 to 9 shows the measurement results of the inverters under investigation. With the reduction in the dclink voltage, the new Dual T-type 5L inverter reduces the voltage stress on the switches by $50 \%\left(V_{S 1}=V_{S 2}=V_{S 1 T}=\right.$ $V_{S 2 T}=V_{d c} / 2 \quad$ and $\left.\quad V_{S 3}=V_{S 4}=V_{S 3 T}=V_{S 4 T}=V_{d c} / 4\right)$ compared to conventional $3 \mathrm{~L}$ T-type inverter $\left(V_{S 1}=V_{S 2}=\right.$ $V_{d c}$ and $\left.V_{S 3}=V_{S 4}=V_{d c} / 2 \mathrm{~V}\right)$, whilst keeping the current stress same. This helps to select a lower voltage device (preferably $650 \mathrm{~V}$ modules with lower cost and lower $R_{D S-o n}$ compared to $1200 \mathrm{~V}$ T-Type module with higher cost and higher $\left.R_{D S-o n}\right)$. The new Dual T-type inverter not only reduce the voltage stress on the device but also reduce the voltage stress on the dc-link capacitors. With the new design, $250 \mathrm{~V}$ capacitor can be implemented compared to $450 \mathrm{~V}$ capacitor for conventional T-type inverter. The efficiency of the new Dual T-Type inverter over a wide range of load is $\approx 99 \%$.

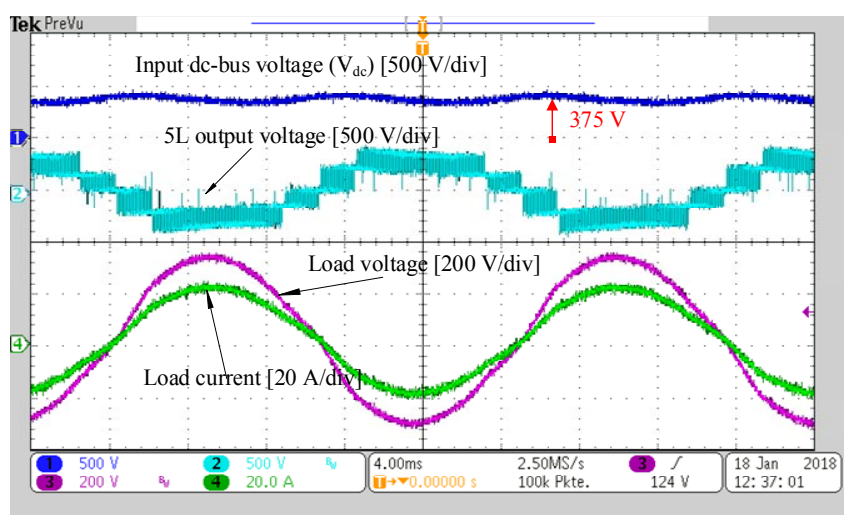

(a)

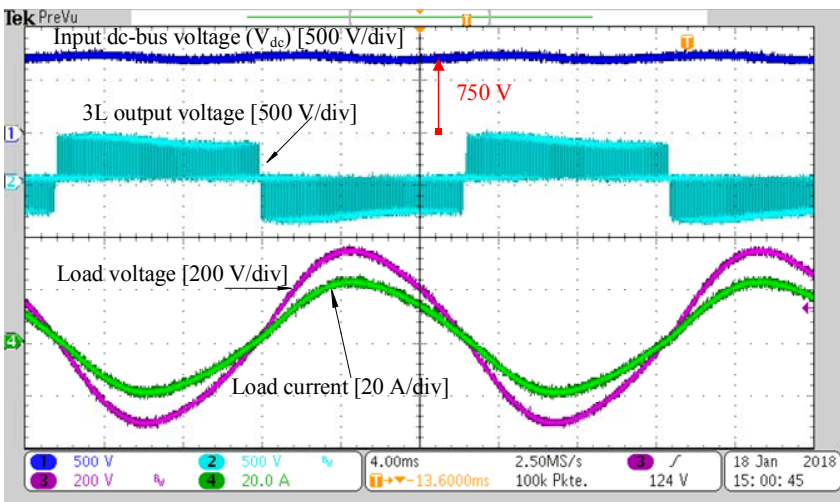

(b)

Fig. 7. Measurement results of 3.3. kW (a) 5L Dual T-type inverter and (b) 3L $\mathrm{T}$-Type inverter showing: input dc-link voltage $\left(V_{d c}=375 \mathrm{~V}\right.$ for $5 \mathrm{~L}$ Dual Ttype inverter and $V_{d c}=750 \mathrm{~V}$ for 3L T-Type inverter), output voltage levels and current.

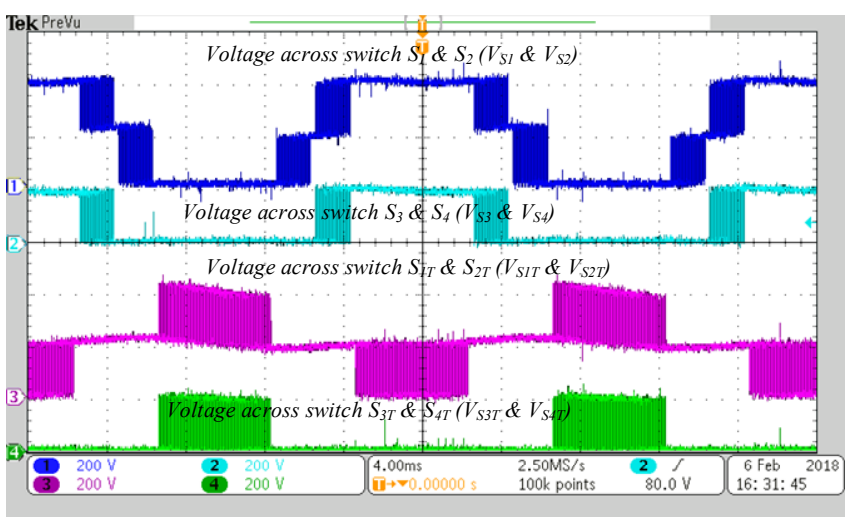

Fig. 8. Measured voltage stress on the switches of 5L Dual T-type inverter. 


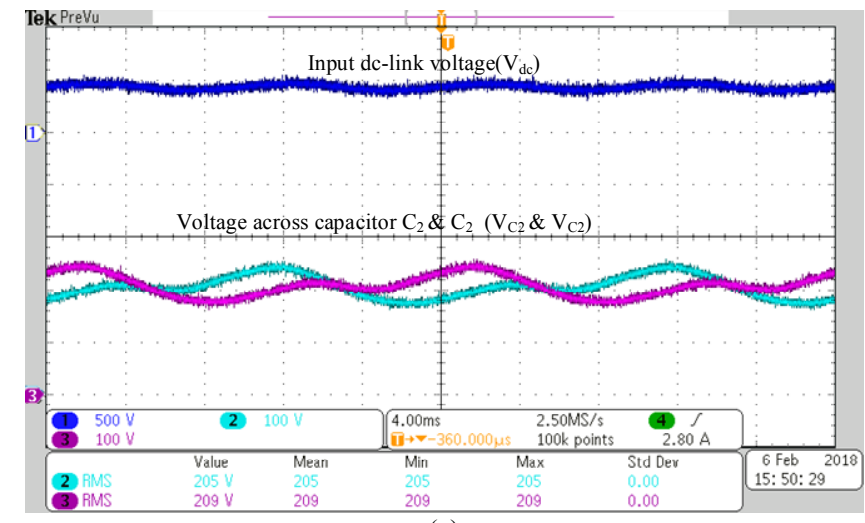

(a)

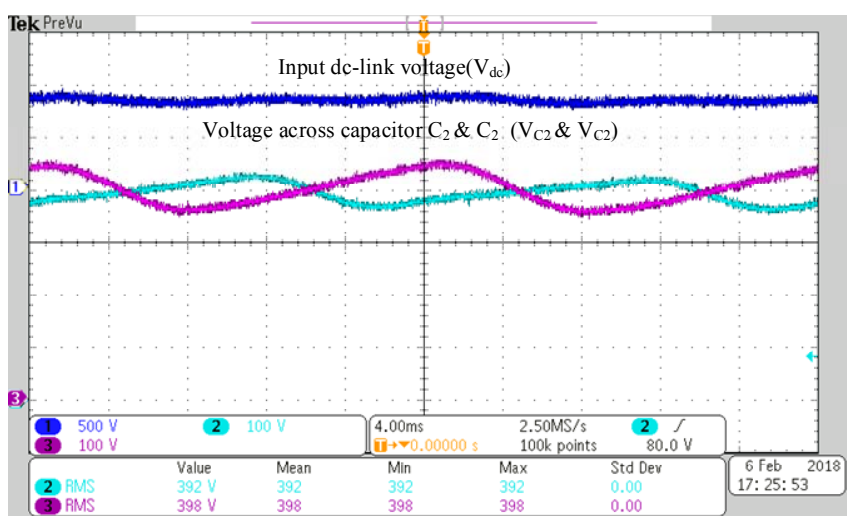

(b)

Fig. 9. Measurement results (a) 5L Dual T-type inverter and (b) 3L T-Type inverter showing: input dc-link voltage ( $V_{d c}=375 \mathrm{~V}$ for 5L Dual T-type inverter and $V_{d c}=750 \mathrm{~V}$ for 3L T-Type inverter), and dc-link capacitor voltages.

\section{CONCLUSION}

To exploit the full potential of the multilevel converter, a generalized model of new class of multilevel inverter has been investigated. The proposed technique has been proved to improve the dc-bus voltage utilization from $50 \%$ to $100 \%$ in any multilevel converter. The associated merits has been highlighted and discussed in details with an application example of 5L Dual T-type inverter resulted from conventional 3L T-Type NPC inverter. Compared to existing multilevel inverter topologies, performance demonstrated by the new inverter are presently incomparable, which makes it appropriate topology for a wide-range of power conversion applications, e.g. telecom power supply, variable-speed drive system, electric vehicles (V2G/G2V technologies), gridconnected renewable energy, etc.

\section{REFERENCES}

[1] F. Z. Peng, "A Generalized Multilevel Inverter Topology with Self Voltage Balancing," IEEE Trans. Ind. Applicat., vol. 37, no. 2, pp. 611618, Mar./Apr. 2001.

[2] J. Rodriguez, J. S. Lai, and F. Z. Peng, "Multilevel Inverters: A Survey of Topologies, Control, and Applications," IEEE Trans. Ind. Electron., vol. 49, no. 4, pp. 724-738, Aug. 2002.

[3] J. Rodriguez, S. Bernet, P. K. Steimer, and I. E. Lizama, "A Survey on Neutral-Point-Clamped Inverters," IEEE Trans. Ind. Electron., vol. 57, no. 7, pp. 2219-2230, Jul. 2010.

[4] S. Kouro, M. Malinowski, K. Gopakumar, J. Pou, L. G. Franquelo, B. Wu, J. Rodriguez, M. A. Perez, and J. I. Leon, "Recent Advances and Industrial Applications of Multilevel Converters," IEEE Trans. Ind. Electron., vol. 57, no. 8, pp. 2553-2580, Aug. 2010.

[5] M. Schweizer, and J. W. Kolar, "Design and Implementation of a Highly Efficient Three-Level T-Type Converter for Low-Voltage Applications," IEEE Trans. Power Electron., vol. 28, no. 2, pp. 899907, Feb. 2013

[6] J. I. Leon, S. Vazquez, and L. G. Franquelo, "Multilevel Converters: Control and Modulation Techniques for their Operation and Industrial Applications," Proceedings of IEEE, vol. 105, no. 11, pp. 2066-2081, Nov. 2017. 